\title{
The role of a diffusion barrier in plasma display panel with the high gamma cathode layer
}

\author{
Tae-Ho Lee, ${ }^{1}$ Hee-Woon Cheong, ${ }^{1}$ Ohyung Kwon, ${ }^{1}$ Ki-Woong Whang, ${ }^{1, a)}$ \\ Sven Ole Steinmüller, ${ }^{2}$ and Jürgen Janek ${ }^{2}$ \\ ${ }^{1}$ Plasma Laboratory, Department of Electrical Engineering and Computer Science, Seoul National University, \\ 599 Gwanak-ro, Gwanak-gu, Seoul 151-742, Korea \\ ${ }^{2}$ Physikalisch-ChemischesInstitut, Justus-Liebig-University Giessen, Heinrich-Buff-Ring 58, D-35392 Giessen, \\ Germany
}

(Received 30 June 2011; accepted 27 September 2011; published online 24 October 2011)

\begin{abstract}
Plasma display panel (PDP) with $\mathrm{MgO}-\mathrm{SrO}$ double cathode layer and $\mathrm{SiO}_{2}$ diffusion barrier is proposed to make the SrO layer free of contaminations. Time of flight-secondary ion mass spectrometry (TOF-SIMS) analysis shows the diffusion of impurities, like $\mathrm{Na}$ and $\mathrm{K}$, can be effectively blocked while a new SrO layer is formed on top of the $\mathrm{MgO}$ layer. This structure shows that high Xe gases can be used to improve the luminous efficacy 2.3 times and decrease the voltage margin more than $10 \mathrm{~V}$ compared to the conventional PDP using $\mathrm{Ne}-\mathrm{Xe} 15 \%$. The aging time was also significantly decreased to 3-4 h. (C) 2011 American Institute of Physics. [doi:10.1063/1.3655329]
\end{abstract}

Plasma display panel (PDP) can provide vivid, high quality images and so is suited for the display of realistic 3dimensional (3D) images. PDP has made big improvements in its luminous efficacy and power consumption over the years, but still needs further progress in order to meet the green products requirements. ${ }^{1}$ One of the effective methods used to reduce the discharge voltage and increase the luminous efficacy of a PDP is to use a high gamma cathode layer. $\mathrm{MgO}$ has been one of the most widely used cathode materials; however, it has limitations because of the large band gap energy of about $7 \mathrm{eV}$, too large to induce the secondary electron emissions through the Auger neutralization process using Xe ions. ${ }^{2-4}$ There have been many attempts to apply other alkaline earth metal oxides such as $\mathrm{SrO}$ and $\mathrm{CaO}$, which have a lower band gap energy and, therefore, a higher secondary electron emission coefficient for $\mathrm{Xe}$ ions when compared to $\mathrm{MgO}{ }^{5,6}$ However, these materials have limitations when applied to PDP using the normal fabrication process, since they are very unstable and highly reactive with $\mathrm{H}_{2} \mathrm{O}$ or $\mathrm{CO}_{2}$, resulting in the formation of hydroxides or carbonates when exposed to air. In a recent research, which used a mixture of $\mathrm{SrO}$ and $\mathrm{CaO}$, the luminous efficacy almost doubledwith a $\mathrm{Ne}-\mathrm{Xe} 30 \%$ content gas compared to that of a panel using the conventional $\mathrm{MgO}$ employing $\mathrm{Ne}$ $\mathrm{Xe} 10 \% .^{4}$ However, the panel assembly fabrication process needed to be carried out in either a nitrogen gas atmosphere or in a vacuum. Another method which does not require a special sealing process but still allows the use of the high gamma property of $\mathrm{SrO}$ or $\mathrm{CaO}$ had been suggested. ${ }^{7}$ It uses a double cathode layer structure consisting of a maincathode layer of an alkaline earth metal oxide like $\mathrm{SrO}$ and a protecting $\mathrm{MgO}$ layer. It has been shown that a panel with the double cathode layer could retain the high gamma properties of the SrO main-cathode layer, so that the high luminous efficacy and low driving voltage could be realized even

\footnotetext{
${ }^{\text {a) }}$ Author to whom correspondence should be addressed. Electronic mail: kwhang@snu.ac.kr.
}

though the conventional sealing process was used. However, the panels with the double cathode layer or binary alloy needed a long aging time of 30-40 h for the stabilization of the discharge voltages, compared to the $\mathrm{MgO}$ single cathode layer panel. ${ }^{7-10}$ Based on the findings from the time of flight-secondary ion mass spectrometry(TOF-SIMS) analysis of the cathode layer, we suggest a diffusion barrier between the dielectric and cathode layers in order to prevent the contamination of the cathode layer by impurities originating from the underlying dielectric layer, electrode, and glass substrate, which occurs during the high temperature sealing process.

The cathode layer is deposited after forming a transparent dielectric layer on front glass substrate. The substrate is then aligned and sealed with a rear glass substrate and sintered at a peak temperature of $450{ }^{\circ} \mathrm{C}$ for $4 \mathrm{~h}$. Finally, the assembled panel undergoes a thermal annealing process at a temperature of $360^{\circ} \mathrm{C}$ for $6 \mathrm{~h}$ in order to outgas and exhaust all of the residual gases. During the sealing and annealing processes, some elements like sodium and potassium come out from the dielectric layer, electrode, and glass substrate and diffuse into the cathode layer, as shown in Fig. 1, which shows the vertical distribution of the elements in the cathode and dielectric layers obtained by TOF-SIMS (TOF-SIMS V, Ion-ToF GmbH). Fig. 1(a) shows the as-deposited layers and (b) the layers after experiencing the high temperature sealing process. Fig. 1(a) shows a clear layer structure for the $\mathrm{MgO}$, $\mathrm{SrO}$, and dielectric layers, whereas an outward diffusion of $\mathrm{Sr}$ through the $\mathrm{MgO}$ layer forms a new SrO I layer on top of the $\mathrm{MgO}$ and at the same time, the diffusion of $\mathrm{Na}, \mathrm{K}$ through the $\mathrm{SrO}$ and $\mathrm{MgO}$ layers accumulates on the surface of the newly formed SrO I layer. In order to reduce the contamination of $\mathrm{SrO}$, a $1 \mu \mathrm{m}$ thick $\mathrm{SiO}_{2}$ layer is inserted as shown in Fig. 2. The plasma-enhanced chemical vapor deposition (PECVD, 310PC, Surface Technology System) method is used in order to deposit $\mathrm{SiO}_{2}$ at $200^{\circ} \mathrm{C}$ with $5 \%$ $\mathrm{SiH}_{4} / \mathrm{N}_{2}(160 \mathrm{sccm}), \mathrm{N}_{2} \mathrm{O}(1500 \mathrm{sccm})$, and $\mathrm{N}_{2}(240 \mathrm{sccm})$ gases at $73.3 \mathrm{~Pa}$. The deposition rate was $34 \mathrm{~nm} / \mathrm{min}$ when 

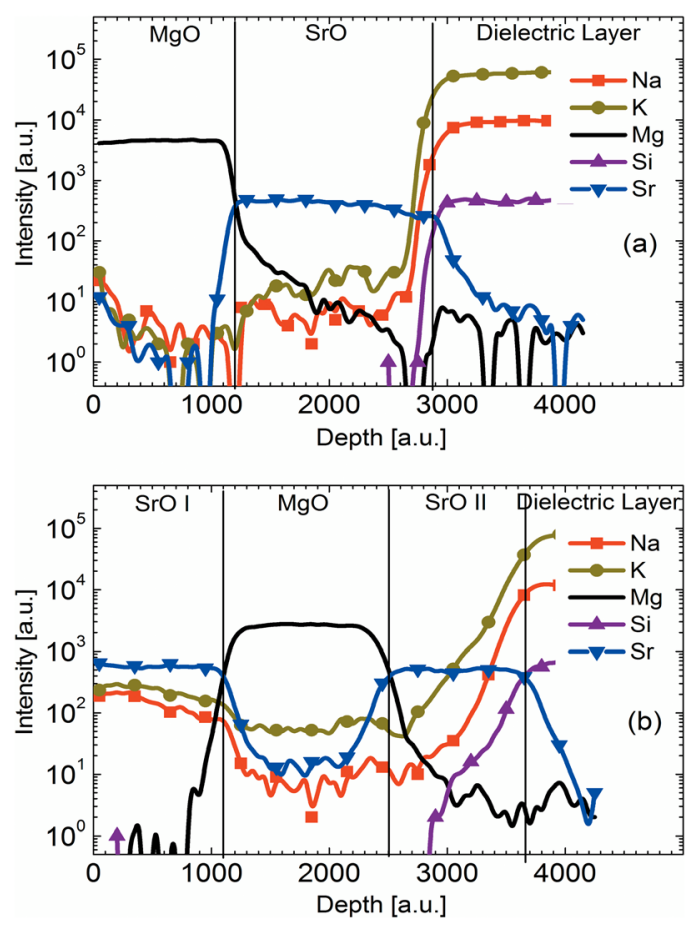

FIG. 1. (Color online) The element distribution obtained by the TOF-SIMS. (a) As-deposited $\mathrm{SrO}-\mathrm{MgO}$ double cathode layer. (b) The same sample after furnace process at $450^{\circ} \mathrm{C}$ for $4 \mathrm{~h}$.

$60 \mathrm{~W}$ of RF power was applied. In order to verify the effect of the diffusion barrier, 2 in. test panels with 50 in. full high definition (FHD) resolution specifications were fabricated and tested for the experiment as shown in Table I.

Fig. 3 shows the vertical distribution of elements in the cathode and dielectric layers of the panels with the $1 \mu \mathrm{m}$ thick $\mathrm{SiO}_{2}$ layer before (Fig. 3(a)) and after (Fig. 3(b)) the $4 \mathrm{~h} 450^{\circ} \mathrm{C}$ high temperature process. Fig. 3(a) shows the clear layer structure of the $\mathrm{SrO}-\mathrm{MgO}$ double cathode with the $\mathrm{SiO}_{2}$ diffusion barrier between the $\mathrm{SrO}$ and dielectric layers. In Fig. 3(b), we can find the Sr diffusion through the $\mathrm{MgO}$ layer and formation of a new SrO I layer on top of the $\mathrm{MgO}$. The diffusion of the $\mathrm{Na}$ and $\mathrm{K}$ through $\mathrm{SiO}_{2}$ is blocked effectively, so that their levels inside of the newly formed SrO I layer are negligible. Fig. 4 shows the luminance and

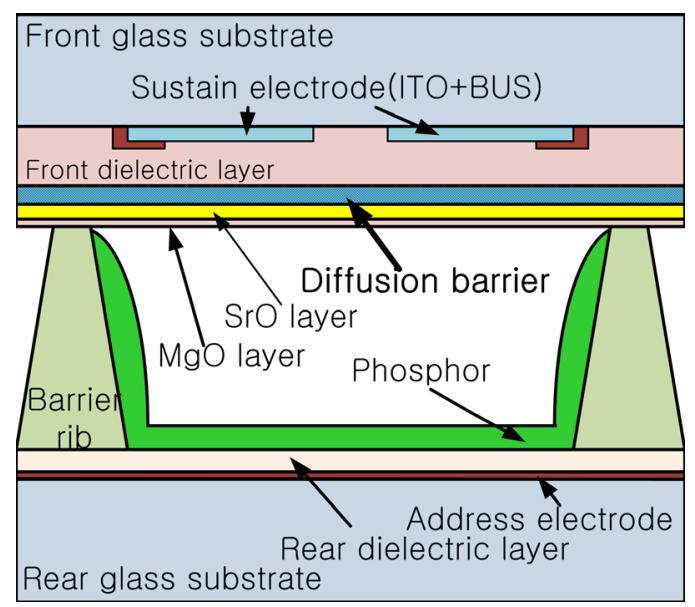

FIG. 2. (Color online) The schematics of suggested double cathode layer with the diffusion barrier.
TABLE I. The test panel specifications.

\begin{tabular}{ll}
\hline \hline Parameter & \multicolumn{1}{c}{ Value } \\
\hline Resolution and cell pitch & $50 \mathrm{in}$. FHD and $576 \mu \mathrm{m}$ \\
Front dielectric & $\epsilon=12$ and $30 \mu \mathrm{m}$ \\
Barrier rib height & $120 \mu \mathrm{m}$ \\
ITO gap & $60 \mu \mathrm{m}$ \\
$\mathrm{MgO}$ layer thickness & $500 \mathrm{~nm}$ \\
SrO-MgO layer thickness & SrO: $500 \mathrm{~nm}, \mathrm{MgO}: 120 \mathrm{~nm}$ \\
Phosphor & Monochrome green \\
Aging conditions & Square pluses $/ 50 \mathrm{kHz}, 300 \mathrm{~V}$ \\
\hline \hline
\end{tabular}

luminous efficacy of the panels with the different types of cathode layers. The reference values are taken from the panel with the single $\mathrm{MgO}$ layer and the $\mathrm{Ne}-\mathrm{Xe} 15 \%$ gas. When a $\mathrm{SrO}-\mathrm{MgO}$ double cathode layer is used, the panel with the $\mathrm{Ne}-\mathrm{Xe} 15 \%$ shows a $20 \mathrm{~V}$ reduction in the lower end of the voltage margin and $40 \%$ increase in the luminous efficacy. However, it took $30-40 \mathrm{~h}$ of aging for this double cathode layer panel to have stabile voltages, as can be seen in Fig. 5, which shows the variation of the firing and sustain voltages according to the aging time for the various types of cathode layers.

When the $\mathrm{SiO}_{2}$ diffusion barrier is adopted, the panel using $\mathrm{Ne}-\mathrm{Xe} 15 \%$ gas shows a $30 \mathrm{~V}$ reduction in the lower end voltage margin and a 55\% increase in the luminous efficacy compared to the reference panel. In addition to these improvements in the voltage margin and luminous efficacy, a more important improvement occurs regarding the aging time, as can be seen in Fig. 5, when the $\mathrm{SiO}_{2}$ diffusion barrier is adopted. It can be seen that the long $30-40$ aging time needed for the panel with the $\mathrm{SrO}-\mathrm{MgO}$ double cathode layer without the diffusion barrier is now reduced to $3-4 \mathrm{~h}$ when
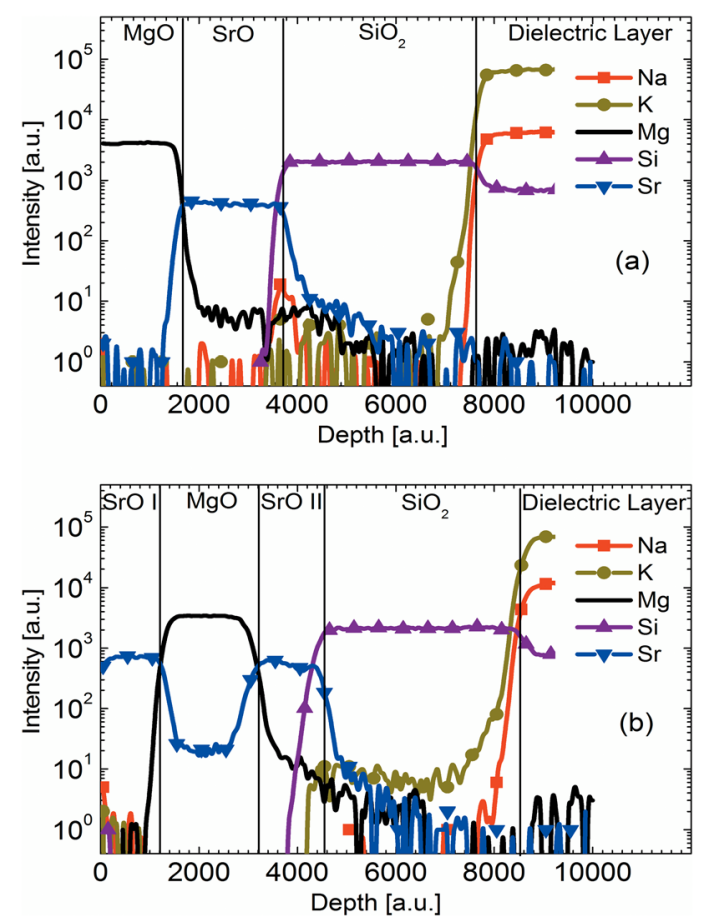

FIG. 3. (Color online) The element distribution obtained by the TOF-SIMS. (a) As-deposited $\mathrm{SrO}-\mathrm{MgO}$ double cathode layer with the $\mathrm{SiO}_{2}$ diffusion barrier. (b) The same sample after furnace process at $450^{\circ} \mathrm{C}$ for $4 \mathrm{~h}$. 


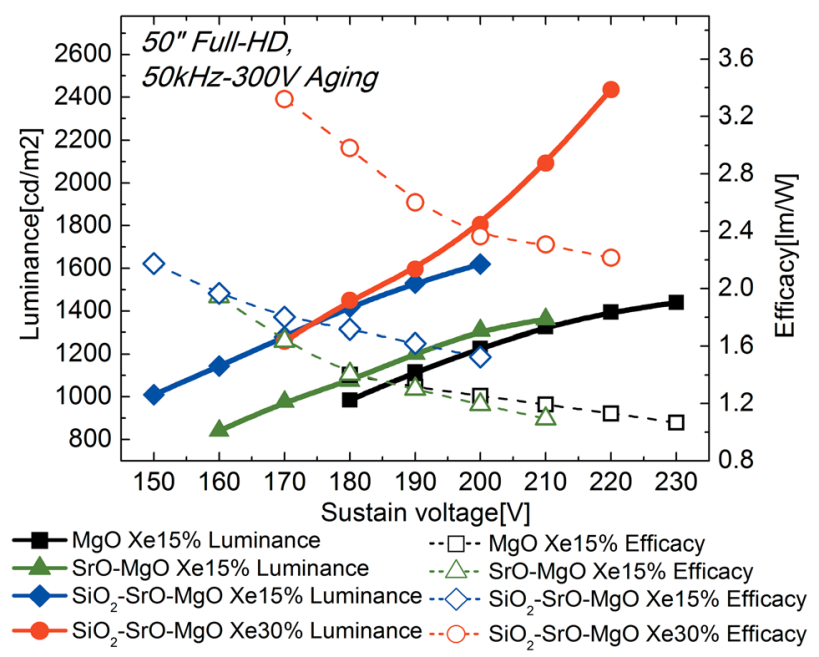

FIG. 4. (Color online) The luminance and luminous efficacy of the various panels.

the $\mathrm{SiO}_{2}$ diffusion barrier is adopted. Fig. 4 also shows that even when the Xe content is increased to $30 \%$, if the panel has the $\mathrm{SrO}-\mathrm{MgO}$ double cathode layer with the diffusion barrier, its lower voltage margin is still smaller by $10 \mathrm{~V}$ but the highest measured luminous efficacy is 2.3 times larger when compared to the reference. Considering that the Xe content in the reference panel is $15 \%$, this low voltage characteristic of panel with $30 \%$ Xe gas markedly shows the benefit of using high a gamma cathode material like SrO. A life time test shows that the PDP with the SrO-MgO double cathode layer exhibits a longer life time than that of one with the traditional $\mathrm{MgO}$ single cathode layer which can be ascribed to the low voltage characteristic of the former one.

In conclusion, the importance of the prevention of contamination in the cathode layer is reported in PDP. Through the analysis of cathode layer using a TOF-SIMS, it has been found that impurities like $\mathrm{Na}$ and $\mathrm{K}$ in the dielectric layer, electrode, and glass substrate diffuse through the cathode layer during the high temperature sealing process and accumulate on the cathode surface, which eventually leads to the increased driving voltage and aging time and decrease in luminous efficacy. This diffusion can be effectively blocked by the adoption of a $\mathrm{SiO}_{2}$ diffusion barrier made using the PECVD method. When the panel adopted this diffusion

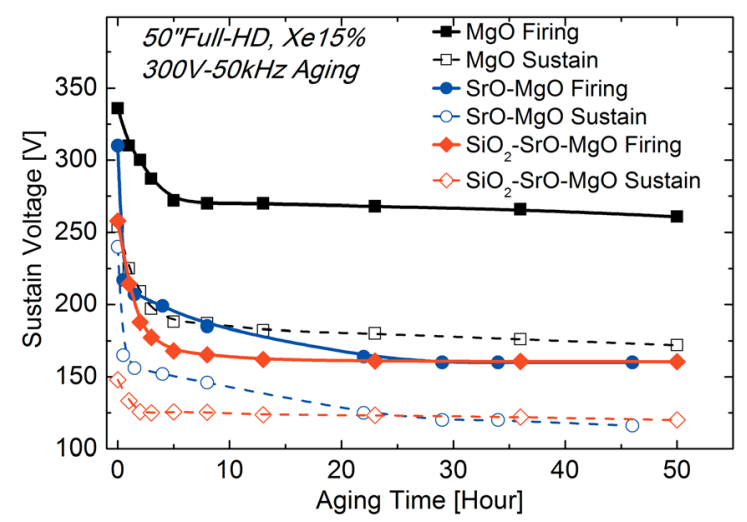

FIG. 5. (Color online) The driving voltage variations according to the aging time with the $\mathrm{MgO}$ single layer, the $\mathrm{SrO}-\mathrm{MgO}$ double layer, and the $\mathrm{SrO}$ $\mathrm{MgO}$ double layer with the $\mathrm{SiO}_{2}$ diffusion barrier.

barrier togetherwith the $\mathrm{SrO}-\mathrm{MgO}$ double cathode layer, it showed one order of magnitude decrease in the aging time and a greatly improved luminous efficacy at reduced voltages when compared to those of the panel equipped with the conventional $\mathrm{MgO}$ cathode layer without the diffusion barrier.

${ }^{1}$ ENERGY STAR ${ }^{\circledR}$ Program Requirements Product Specification for Televisions, Eligibility CriteriaVersion 5.3, U.S. Environmental Protection Agency.

${ }^{2}$ G. Oversluizen, T. Dekker, M. F. Gillies, and S. T. de Zwart, J. Soc. Inf. Disp. 12, 51 (2004).

${ }^{3}$ G. Oversluizen, S. de Zwart, T. Dekker, and M. F. Gillies, in Digest of Technical Papers of 2002 Society for Information Display International Symposium (Society for Information Display, Boston, 2002), p. 848.

${ }^{4}$ Y. Motoyama, Y. Murakami, M. Seki, T. Kurauchi, and N. Kikuchi, IEEE Trans. Plasma Sci. 54, 1308 (2007).

${ }^{5}$ T. Shinoda, H. Uchiike, and S. Andoh, IEEE Trans. Electron Devices 26, 1163 (1979).

${ }^{6}$ H. Uchiike, K. Sekiya, T. Hashimoto, T. Shinoda, and Y. Fukushima, IEEE Trans. Electron Devices 30, 1735 (1983).

${ }^{7}$ K. Whang, H. Jung, T. Lee, and H. Cheong, in Proceeding of the 10th International Meeting on Information Display (Korean Information Display Society, Ilsan, Korea, 2009), p. 173.

${ }^{8}$ Y. Motoyama, D. Kato, and M. Seki, in Proceedings of the 17th International Display Workshop (Society for Information Display, Fukuoka, Japan, 2010), p. 959.

${ }^{9}$ H. Jung, T. Lee, O. Kwon, H. Cheong, S. Steinmüller, J. Janek, and K. Whang, IEEE Electron Device Lett. 31, 686 (2010).

${ }^{10}$ K. Kim, J. Kim, J. Tang, K. Whang, and S. Lee, J. Kor. Vac. Soc. 8, 482 (1999). 